\title{
Integrated Application of Cleaner Production on a University Campus
}

\author{
Johnny Nahui-Ortiz, Ph.D. ${ }^{1}$, Caroline Camarena-Gamarra ${ }^{1}$, Alejandro Mendoza ${ }^{1}$ \\ 1National University of Engineering, Peru, jnahuio@uni.edu.pe, ccamarenag@uni.pe, amen807@hotmail.com
}

\begin{abstract}
Cleaner production is gaining increased attention worldwide. The objective of the present work is the integrated application of cleaner production on a university campus. A university campus involves several activities including academic and administrative tasks that are carried out along the entire year.

Opportunities for efficient use of energy, water, fuels, and other resources, are identified in order to establish the cost-benefit associated with its eventual implementation. Their feasibility evaluation should consider technological, economic, and environmental aspects involved in order to assess potential cost savings and the corresponding payback time.

Potential impacts on utility bills can be rather significant and depend on the nature of the cleaner production strategy to be implemented, including best practices, replacement of current equipment and components with more efficient units, as well as adoption of best available technologies.

Annual usage of energy, water, fuels, ink, and paper on a university campus was collected. It was found that total annual cost accounted for 1'471,863 US\$. Potential annual cost savings were estimated as 267,304 USS. Implementation cost was estimated as 276,200 US\$ with an overall payback time of 1.03 years. In addition to that, cleaner production measures for electricity and fuels would lead to a carbon dioxide emissions reduction of 57.27 tons/yr.
\end{abstract}

$\begin{aligned} & \text { Keywords-Educational Facilities, Cleaner Production, } \\ & \text { Resource Conservation, } \\ & \text { Ecoefficiency. }\end{aligned}$
Environmental Management,

\section{INTRODUCTION}

A research group named "Energy and Sustainable Development" was formed at the Environmental Engineering Department in the National University of Engineering (FIAUNI) by a team of lecturers and students. The nature of activities that take place in a university campus requires quite a few resources; therefore, their optimization is a must. Cleaner production appears as a potential tool in order to achieve such task. A previous work from the aforementioned research group focused on developing a suitable methodology in order to apply effectively cleaner production strategies on a university campus. Thus, the present work concentrates in an integrated application of such proposed methodology.

\section{A. University Campus activities}

A number of different activities are carried out within a university campus, including academic, administrative, and other tasks.

Digital Object Identifier (DOI):

http://dx.doi.org/10.18687/LACCEI2020.1.1.157

ISBN: 978-958-52071-4-1 ISSN: 2414-6390
For academic purposes, electricity is needed for lighting in classrooms as well as for operating a few air conditioning units that are used in auditoriums and the kind. Electric power is also used in a few laboratories that belong to the distinct engineering schools including mechanical, electrical, industrial, chemical, and petroleum engineering departments. Water is also used in the restrooms for both students and lectures. In addition to that, water is consumed by a few laboratories that belong to both engineering departments and also science departments, including physics, chemistry and physic-chemistry departments.

For administrative purposes, electricity is also needed for lighting in offices that are used by staff members as well as lecturers and some students. Electricity is also consumed by some air conditioning units, as well as some appliances such computers, printers, photocopy machines, microwave ovens, and coffee machines. Water is also used in restrooms that belong to administrative areas.

Several transportation units, including buses and light vehicles, are used on campus for transporting students and authorities inside campus, and also outside campus in order to conduct external activities. Those transportation units use diesel oil (DB5), compressed natural gas (CNG), and gasolines (both G90 and G95).

Other resources are also used for academic and administrative purposes. Such resources include ink and paper. Ink is used for printers and photocopy machines. It is noted that different types of papers are uses including bond, bulky, and others.

\section{B. Background on Cleaner Production}

In Ref. [01], it is stated that efforts on defining and solving problems with the special accent upon a sustainable solution for the use of raw materials and energy, technological advances, product and policy changes are presented and deeply discussed. Multiple examples are provided relating the successful combination of cleaner production in policy structures, illustrating on how the focused work in production sectors is delivering multiplier benefits and creating conditions to facilitate a "leapfrogged" path toward Sustainable Development.

In Ref. [02], the authors focus on defining and solving problems with special emphasis upon sustainability strategies: raw material replacement, renewable energy, technological developments, product, and policy changes. Multiple examples of successful integration of Cleaner Production in national and local policy structures, exemplified how focused work in key industrial sectors is delivering multiplier benefits within and among companies and in the community, at large. 
In Ref. [03], a special focus is placed upon methodological tools designed to support effective decisionmaking pertaining to quantitative benefits from Cleaner Production. Papers cover the importance of informal knowledge, as complementary to formal knowledge, in performing effective 'Environmental Impact Assessments.'

According to Ref. [04], the findings range from proposals for alternative uses of wastes, substitution of raw materials for environmentally friendlier substances, optimization of industrial processes by source reductions of wastes and emissions and documented economic and environmental advantages of a wide array of initiatives. The roles of operational and managerial practices are also stressed, highlighting the role of diverse stakeholders as promoters of implementation and internalization of innovative cleaner technologies within companies.

According to Ref. [05], Cleaner Production is an important means for systematically reducing waste. For its successful implementation, it is essential to ensure the effectiveness of the factors that can influence this process, such as the identification of decision criteria and an effective methodology for managing projects and implementing strategies to reach expected results.

According to Ref. [06], "Cleaner Production" is about less and more efficient energy and materials use and the substitution of more harmful products (for the environment and health) by less dangerous ones. This widening of contents necessitates more and better-adapted methods supporting the measurement of the Cleaner Production components. Indicators, assessment strategies, and green accounting are increasingly improved and used more specifically and frequently.

In Ref. [07], it is stated that Cleaner Production is a fastgrowing area with numerous important developments seen over the years, which have led to substantial improvements, both in technological, process and organization terms. Yet there is a paucity of literature organizing the body of knowledge on the benefits and difficulties seen in this field.

According to Ref. [08], the concept of Cleaner Production has been hailed for the several economic, environmental and social benefits it can provide. However, the implementation of Cleaner Production programs continues facing problems and barriers, such as the lack of detailed information, tools and techniques that can be employed systematically to achieve the desired results.

According to Ref. [09], Cleaner Production allowed businesses to visualize the concept of environmental sustainability in practice and to believe in the possibility of producing more with less, besides reducing environmental costs. However, although cleaner production has already been accepted and is increasingly applied, it is not a standard procedure for managing environmental aspects.

In Ref. [10], it is stated that Cleaner Production assessment is an essential part of cleaner production methodologies. To date, a number of different methods have been developed for or applied to cleaner production assessment. Although there is no inherently better or worse tool, cleaner production assessment should fully consider the inherent attributes of cleaner production itself. One prominent attribute of cleaner production is the relativity of cleanliness, considering it made cleaner production assessment more understandable

\section{METHODOLOGY}

\section{A. Cleaner Production Approach for University Campus}

In a previous work carried out by the same research group, a methodology was developed in order to facilitate the effective application of cleaner production on a university campus. Ref. [14].

The following figure summarizes the proposed methodology.

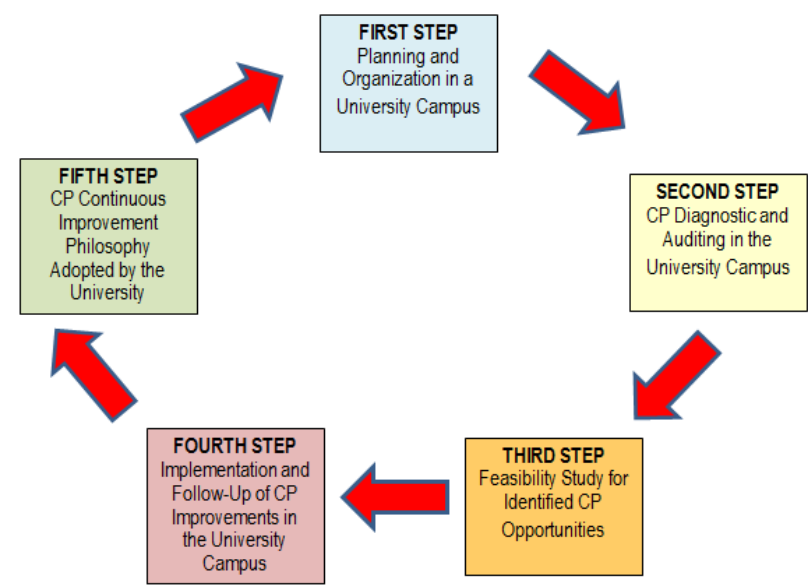

Fig. 1 A proposed Cleaner Production methodology for a university campus. Ref. [14].

The first step in the methodology consists in planning and organizing. This is particularly relevant in the case of a university campus since there are different academic departments and administrative areas. Also, there exist other facilities including laboratories and sport-related installations. An important aspect is to pay attention to daily operations and availability of personnel to be interviewed and to access the different areas in order to collect relevant data.

The second step involves a diagnostic of current situation and, even more important, the identification of strategies and opportunities for improvement in terms of cleaner production. Those opportunities may include best practices, replacement of a current equipment or component with a more efficient one, as well as adapting innovative technologies.

The third step focuses con determining which opportunities are feasible for implementation based on a realistic cost-benefit analysis. Definition of a reasonable payback period depends on internal policies as to how funds are administered within a university campus.

The fourth step deals with implementation of selected feasible opportunities and, as equally important, with the follow-up of anticipated impacts after implementation. The 
basic idea is to determine whether the previously calculated cost-benefit can be later verified under actual operating conditions.

Last but not least, the fifth step deals with application of the philosophy of continuous improvement which includes decision-making processes in order to correct possible deviations from expected cost savings and, at the same time, the process of looking for additional cost-savings opportunities.

\section{B. Data Collection}

For data collection purposes, the university campus was mapped and divided into areas that belong to each engineering department. For instance, letter "A" belongs to Mechanical Engineering Department, letter " $C$ " belongs to Chemical Engineering Department, letter " $\mathrm{D}$ " belongs to Environmental Engineering Department, and so on. In total, the university campus currently has 11 Engineering Departments that contains 28 major careers and occupies a surface of 666,000 $\mathrm{m}^{2}$.

Several walk-throughs were conducted to identify major equipment and components associated with electricity, water, and paper/ink consumption. Nameplate data was taken directly in most appliances but operating hours were established on the basis of interviews with personnel from each area considered in the assessment. Also, electricity, water, and fuel bills were collected and analyzed in order to establish monthly consumption and related costs. Besides, expenses in ink and paper were obtained from public records.

The following figure illustrates the level of detail considered for collecting relevant data.

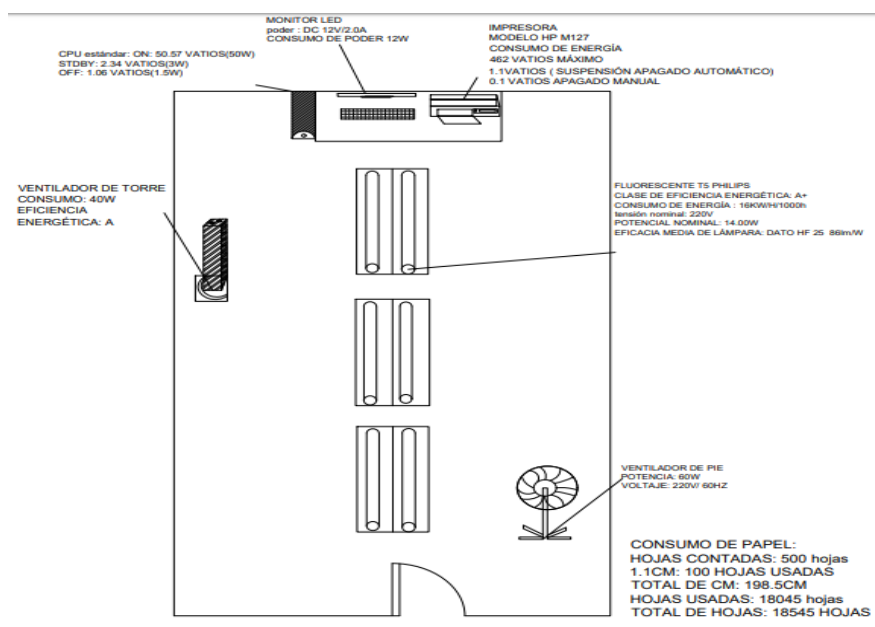

Fig. 2 Sample of data for a specific office area in the university campus

\section{RESOURCE CONSUMPTION}

\section{A. Electricity}

Average monthly consumption is $429,645 \mathrm{kWh}$ (during off-peak hours) and $110,428 \mathrm{kWh}$ (during peak hours). In
Peru, peak hours run from $18 \mathrm{~h} 00$ to $23 \mathrm{~h} 00$ while off-peak hours are referred to the rest of the day. Electricity unit cost varies as a function of peak and off-peak time. Also, it should be noticed that electricity unit cost for the end-user includes a cost for demand power measured in $\mathrm{kW}$, in addition to energy consumed with is measure in $\mathrm{kWh}$.

In this case, average electric power demand is estimated as $753.8 \mathrm{~kW}$ for off-peak hours and $736.2 \mathrm{~kW}$ for peak hours. Average monthly cost of electricity is 71,190 US\$ which leads to an electricity unit cost of $0.132 \mathrm{US} \$ / \mathrm{kWh}$.

\section{B. Water}

Average monthly consumption of water on campus accounts for $44,919 \mathrm{~m}^{3}$. Also, average monthly cost of water consumption is 31,331 US\$. Thus, the unit water cost turns out to be $0.698 \mathrm{US} \$ / \mathrm{m}^{3}$.

TABLE I

ELECTRICITY, WATER, AND CNG MONTHLY CONSUMPTION

\begin{tabular}{|c|c|c|c|c|c|}
\hline \multicolumn{2}{|c|}{ Electricity } & \multicolumn{2}{c|}{ Water } & \multicolumn{2}{c|}{ CNG } \\
\hline 540,073 & $\mathrm{kWh}$ & 44,919 & $\mathrm{~m} 3$ & 827 & $\mathrm{sm}^{3}$ \\
\hline 71,190 & $\mathrm{US} \$$ & 31,331 & $\mathrm{US} \$$ & 484 & $\mathrm{US} \$$ \\
\hline 0.132 & $\$ / \mathrm{kWh}$ & 0.698 & $\mathrm{US} \$ / \mathrm{m}^{3}$ & 0.585 & $\mathrm{US} \$ / \mathrm{sm}^{3}$ \\
\hline
\end{tabular}

Average monthly consumption for electricity, water, and compressed natural gas can be seen in Table I.

\section{Fuels}

Different fuel sources are consumed on campus, including Compressed Natural Gas, Diesel Oil, Gasoline 90 and Gasoline 95. With regard to Diesel Oil, regulations in Peru have established that it must be blended with $5 \%$ from biodiesel. And, with regard to Gasolines, regulations in Peru have established that they must be blended with $7.8 \%$ from ethanol.

Average monthly consumption of Compressed Natural Gas accounts for $827 \mathrm{sm}^{3}$ at a total monthly cost of 484 US\$ with gives a unit fuel cost of $0.585 \mathrm{US} \$ / \mathrm{sm}^{3}$. Also, average monthly consumption of Diesel Oil accounts for 723 gallons at a total monthly cost of 2,634 US\$ which gives a unit fuel cost of $3.643 \mathrm{US} \$ /$ gal. Besides, average monthly consumption of Gasoline 90 accounts for 190 gallons at a total monthly cost of 697 US\$ which gives a unit fuel cost of $3.668 \mathrm{US} \$ /$ gal. Moreover, average monthly consumption of Gasoline 95 accounts for 88 gallons at a total monthly cost of 392 US\$ which gives a unit fuel cost of $4.454 \mathrm{US} \$ /$ gal.

\section{Paper and Ink}

Different kind of paper are used on campus, for academic and administrative purposes, including those related to Bond and Bulky type. Average monthly cost of paper consumption on campus accounts for 5,382 US\$. Also, average monthly cost of ink (for printers and photocopy machines) accounts for 13,663 US\$. 
Average monthly consumption for diesel oil, gasoline 90, and gasoline 95 can be seen in Table II.

TABLE II

DiESEL OIL AND GASOLINES MONTHLY CONSUMPTION

\begin{tabular}{|c|c|c|c|c|c|}
\hline \multicolumn{2}{|c|}{ DB5 } & \multicolumn{2}{c|}{ G90 } & \multicolumn{2}{c|}{ G95 } \\
\hline 723 & gal & 190 & gal & 88 & gal \\
\hline 2634 & US\$ & 697 & US\$ & 392 & US\$ \\
\hline 3.643 & US\$/gal & 3.668 & US\$/gal & 4.454 & US\$/gal \\
\hline
\end{tabular}

\section{OPPORTUNITIES FOR IMPROVEMENT}

There are a number of opportunities that may be found on a university campus in order to accomplish cost savings at a reasonable payback period. However, their feasibility depends on technology availability as well as cost of the resources in use. Besides the technical and economic aspects, there is also a growing environmental concern that needs to be taken into account.

\section{A. Potential Savings}

Annual electricity consumption is estimated as 6' 480,874 $\mathrm{kWh}$. Energy efficiency measures can be applied to lighting systems, including replacement of current lamps with more efficient units. Also, new technologies for lamps have longer operating hours. Besides, electronic ballasts contribute also to increase energy efficiency. Moreover, the use of occupancy sensors can also add to potential savings. Apart from that, energy efficiency can also be applied to air conditioning units including control of the thermostat temperature and use of more efficient units with variable speed controls. There is also an issue associated with common practices that involve leaving doors and windows open while air conditioning units are running. This issue has to be addressed in order to avoid significant energy losses. Electricity consumption during peak hours also needs to be monitored, in order to avoid significant charges in the electricity bill. In this case, it is estimated that a potential cost savings of $15 \%$ could be achieved by promoting a more efficient use of electricity on campus.

With regard to water usage, an annual consumption of 539,023 gallons was registered. Water savings measures can be applied to restrooms and similar areas by using more efficient units in toilets and washing basins. Leaks due to lack of maintenance were detected. Also, it was noted that some users left water flowing unattended for some time without using it. Therefore, there are several opportunities for significant water savings by promoting best practices and by fixing water leaks. In this case, it is estimated that a potential cost savings of $25 \%$ could be accomplished by promoting a more efficient use of water on campus.

In terms of fuel usage, an annual consumption of 8,676 gallons of diesel oil was registered. Also, an annual consumption of $9,927 \mathrm{sm}^{3}$ of compressed natural gas was recorded. Besides, an annual consumption of 2,278 gallons of gasoline 90 was identified. Moreover, 1,060 gallons of gasoline 95 was noted. It is expected that there might some potential savings by improving maintenance of transportation units as well as driving techniques. However, the larger fraction of cost savings would be associated with fuel switching due to price differences between compressed natural gas and other fuels under local market conditions. Potential savings would come as a result of substituting gasolines with compressed natural gas using a relatively simple conversion kit. The same conversion cannot be carried out in units that are presently running on diesel oil. In the case of switching from gasoline 90 to $\mathrm{CNG}$, potential cost savings are estimated as $55 \%$. However, in the case of switching from gasoline 95 to CNG, potential cost savings are estimated as $65 \%$.

Also, consumption of ink and paper was reported in terms of annual monetary expenses, accounting for 163,954 US\$ and 64,584 US\$, respectively. Ink is used mainly for printers and photocopy machines while paper is used mainly for administrative tasks as well as for written exams and the kind. A significant potential savings associated with paper usage would involve using both sides of a sheet of paper. Also, a more significant opportunity would be associated with implementation of digital formats in order to replace current process based on printed matter. In this case, potential cost savings would be considered as $15 \%$ for ink usage and $20 \%$ for paper usage.

\section{B. Cost-Benefit Analysis}

A cost-benefit analysis can be carried out on the basis of simple payback, considering estimated implementation cost (in US\$) and expected annual cost savings (in US\$/yr). By doing so, simple payback can be expressed in terms of how many months or years are required in order to recover the initial amount invested.

With regard to electricity consumption, current annual cost is 854,283 US\$ and it is estimated that potential annual cost savings could reach 128,142 US\$. Implementation cost is estimated as 185,000 US\$, including purchase of new equipment and components plus installation costs, and training sessions for best practices associated with a more efficient use of electricity.

In terms of water consumption, current annual cost is 375,974 US\$ and it is estimated that potential annual cost savings could reach 93,993 US\$. Implementation cost is estimated as 77,500 US\$, including purchase of new accessories, improved maintenance, and workshops for awareness about excessive use of water. Table III shows potential cost savings for electricity and water consumption.

TABLE III

ELECTRICITY AND WATER POTENTIAL COST SAVINGS

\begin{tabular}{|l|c|c|}
\hline \multicolumn{1}{|c|}{ ITEM } & ELECTRICITY & WATER \\
\hline Current Cost (US\$/yr) & 854,283 & 375,974 \\
\hline Potential Cost Savings (\%) & $15 \%$ & $25 \%$ \\
\hline Cost Savings (US\$/yr) & 128,142 & 93,993 \\
\hline Implementation Cost (US\$) & 185,000 & 77,500 \\
\hline Simple Payback (yrs) & 1.44 & 0.82 \\
\hline
\end{tabular}


In the case of fuel consumption, current annual cost is 8,363 US\$ for gasoline 90 and 4,704 US\$ for gasoline 95. And, it is estimated that potential annual cost savings could reach 4,600 US\$ and 3,058 US\$, respectively. Implementation cost in each case would be 5,550 US\$ and 2,650 US\$, respectively. The implementation cost includes the purchase and installation of a conversion kit for light vehicles in order to allow them to use compressed natural gas instead of gasolines. Table IV shows potential cost savings for gasolines consumption.

TABLE IV

GASOLINE 90 AND 95 POTENTIAL COST SAVINGS

\begin{tabular}{|l|c|c|}
\hline \multicolumn{1}{|c|}{ ITEM } & G90 & G95 \\
\hline Current Cost (US\$/yr) & 8,363 & 4,704 \\
\hline Potential Cost Savings (\%) & $55 \%$ & $65 \%$ \\
\hline Cost Savings (US\$/yr) & 4,600 & 3,058 \\
\hline Implementation Cost (US\$) & 5,550 & 2,650 \\
\hline Simple Payback (yrs) & 1.21 & 0.87 \\
\hline
\end{tabular}

Last but not least, current annual expenses in ink and paper are 163,954 US\$ and 64,584 US\$, respectively and it is estimated that potential annual cost savings could reach 24,593 US\$ and 12,917 US\$, respectively. Implementation cost is estimated as 3,000 US\$ and 2,500 US\$, respectively. In this case, implementation cost is associated with planning and organizing tasks instead of purchasing items. Careful decisionmaking process is required in order to switch from using printed documents to digital forms, without affecting the dayto-day activities on campus. Table $\mathrm{V}$ shows potential cost savings for ink and paper usage.

TABLE IV

INK AND PAPER POTENTIAL COST SAVINGS

\begin{tabular}{|l|c|c|}
\hline \multicolumn{1}{|c|}{ ITEM } & INK & PAPER \\
\hline Current Cost (US\$/yr) & 163954 & 64584 \\
\hline Potential Cost Savings (\%) & $15 \%$ & $20 \%$ \\
\hline Cost Savings (US\$/yr) & 24593 & 12917 \\
\hline Implementation Cost (US\$) & 3000 & 2500 \\
\hline Simple Payback (yrs) & 0.12 & 0.19 \\
\hline
\end{tabular}

In summary, it might be said that total current annual cost on campus is around 1'471,863 US\$ for using electricity, water, fuels, ink and paper. Total potential annual cost savings is estimated as 267,304 US\$ which represents $18.2 \%$ of current annual cost. Implementation cost, in order to achieve the above potential cost savings, would account for 276,200 US\$. Thus, an overall payback of $1.03 \mathrm{yr}$ is obtained.

Annual consumption of gasolines currently involves an emission of $2.563 \mathrm{tCO}_{2} / \mathrm{yr}$. If gasolines are replaced with compressed natural gas, emissions would be reduced to 2.002 $\mathrm{tCO}_{2} / \mathrm{yr}$.
Current $\mathrm{CO}_{2}$ emission factor for national electric grid is estimated as $0.7 \mathrm{tCO}_{2} / \mathrm{MWh}$. Therefore, annual consumption of electricity currently involves an emission of $378.1 \mathrm{tCO}_{2} / \mathrm{yr}$. If cleaner production measures were implemented in order to accomplish a more efficient use of electricity, emissions would be reduced to $321.3 \mathrm{tCO}_{2} / \mathrm{yr}$.

\section{CONCLUSIONS}

Activities related to a university campus require a significant consumption of different resources, including electricity, water, fuels, paper, and ink.

Annual consumption was registered for electricity $(540,073 \mathrm{kWh})$, water $\left(44,919 \mathrm{~m}^{3}\right), \mathrm{CNG}\left(827 \mathrm{sm}^{3}\right)$, DB5 $(723$ gal), G90 (190 gal), and G95 (88 gal).

Annual cost associated with resources consumption accounted for 854,283 US\$ (electricity), 375,974 US\$ (water), 5808 US\$ (CNG), 31609 US\$ (DB5), 8363 US\$ (G90), and 4704 US\$ (G95), 163954 US\$ (Ink), and 64584 US\$ (paper).

Considering total usage and related cost, a unit cost for each resource was calculated. The outcome of such calculation was $0.132 \$ / \mathrm{kWh}$ (electricity), $0.698 \mathrm{US} \$ / \mathrm{m}^{3}$ (water), 0.585 US\$/sm ${ }^{3}$ (CNG), 3.643 US\$/gal, $3.668 \mathrm{US} \$ /$ gal (G90), and 4.454 US\$/gal (G95). Unit cost associated with each resource is useful for benchmarking purposes among organizations.

There are several opportunities associated with cleaner production strategies in order promote a more efficient use of resources and to realize potential cost savings. It is estimated that by implementing cleaner production measures, cost savings could be achieved in the use of electricity (15\%), water $(25 \%)$, gasoline $90(55 \%)$, and gasoline $95(65 \%)$.

Annual cost savings were estimated as 128,142 US\$ (electricity), 93,993 US\$ (water), 4,600 US\$(G90), 3,058 US\$(G95), 24,593 US\$ (Ink), and 12,917 US\$ (paper).

In order to achieve those potential cost savings, implementation costs were established as 185,000 US\$ (electricity), 77,500 US\$ (water), 5,550 US\$ (G90), 2,650 US\$ (G95), 3,000 US\$ (Ink), and 2,500 US\$ (paper).

Furthermore, simple payback in years associated with implementation of cleaner production strategies in order to achieve the above potential cost savings were calculated as 1.44 (electricity), 0.82 (water), 1.21 (gasoline 90), 0.87 (gasoline 95), 0.12 (ink), and 0.19 (paper). The calculated payback can be a criterion in order to establish priorities for implementation of cleaner production measures.

An integrated application of cleaner production $o$ a university campus can result in feasible opportunities to contribute to a more sustainable development including technical, economic and, environmental benefits.

Potential cost savings is estimated as $18.2 \%$ of total current annual expenses with an overall payback of 1.03 yrs. Also, carbon dioxide emissions could be reduced by 57.27 $\mathrm{tCO}_{2} / \mathrm{yr}$. 
Last but not least, two-way interaction of lecturers and students with staff members and other people was a very rich experience in educational terms for everyone involved.

\section{ACKNOWLEDGMENT}

The authors would like to thank the staff members and authorities of the Environmental Engineering Department at the National University of Engineering for sharing their time and experience with the research team in order to facilitate data collection. The authors would also like to thank to all the people that, in one way or another, contributed to the present work.

\section{REFERENCES}

[1] ALMEIDA C.M.V.B., AGOSTINHO F., HUISINGH D., GIANNETTI B.F. Cleaner Production towards a sustainable transition. Brazil. 2017.

[2] ALMEIDA C.M.V.B., AGOSTINHO F., GIANNETTI B.F., HUISINGH D., Integrating cleaner production into sustainability strategies: an introduction to this special volume. Universidade Paulista (UNIP). Brazil. 2015.

[3] BONILLA Silvia, ALMEIDA Cecilia, GIANNETTI B.F., HUISINGH D. The roles of cleaner production in the sustainable development of modern societies: an introduction to this special issue. Universidade Paulista. Brazil. 2010.

[4] ALMEIDA Cecilia, BONILLA Silvia, GIANNETTI B.F., HUISINGH. 2013. Cleaner Production initiatives and challenges for a sustainable world: an introduction to this special volume. 2013.

[5] GUIMARAES Julio, SEVERO Eliana, VIEIRA Pedro. Cleaner production, project management and Strategic Drivers: An empirical study. Fundação Meridional (IMED). 2017.

[6] HENS L, BLOCK C., CABELLO-ERAS J. J., SAGASTUMEGUTIEREZ A., VANDECASTEELE C. On the evolution of "CLEANER PRODUCTION" as a concept and a practice. Vlaamse Instelling voor Technologisch Onderzoek. Belgium. 2018.

[7] MATOS Lucas, ANHOLON Rosley, SILVA Dirceu, ORDONEZ Robert, SANTA-EULALIA Luis. Implementation of Cleaner Production: a ten-year retrospective on benefits and difficulties found. State University of Campinas, Brazil. 2018.

[8] SILVA Diogo, DELAI Ivete, CASTRO Marco, OMETTO Aldo. Quality tools applied to Cleaner Production programs: a first approach toward a new methodology. Brazil. 2013.

[9] VIEIRA Leticia, AMARAL Fernando. Barriers and strategies applying Cleaner Production: a Systematic Review. Universidade Federal do Rio Grande do Sul. 2016.

[10] ZHANG Peilei, DUAN Ning, DAN Zhigang, SHI Feifei, WANG Huifeng. An understandable and practicable cleaner production assessment model. School of Environment, Tsinghua University. China. 2018.

[11] INACAL. Guía de Producción Más Limpia. Lima-Perú. 2007.

[12] INACAL Auditoría de Producción Más Limpia, Lima-Perú. 2008.

[13] MINAM. Guía de Eco-eficiencia en Edificios Públicos. Lima-Perú. 2016.

[14] NAHUI-ORTIZ Johnny, MENDOZA Alejandro, SOTELO Freddy. A Methodology for Cleaner Production Implementation at a University Campus in Lima, Peru. National University of Engineering. Lima-Perú. 2018. 